\title{
Construction of Interactive Teaching System for Exercise Training Based on Education Video Resource Push Technology
}

\author{
https://doi.org/10.3991/ijet.v12i07.7217 \\ Lizheng Zhang \\ Beijing City University, Beijing, China \\ zlzcsxy@sina.com \\ Fatao Wang* \\ College of Arts and Science, Beijing Union University, Beijing, China \\ wftbldesina.com \\ Aili Qi \\ Guizhou University of Engineering Science, Bijie, China \\ qiailili@yeah.net
}

\begin{abstract}
Due to imbalanced PE teaching resources and single mode, PE teaching development lags behind. With the help of multimedia technology, an interactive system based on resource push was constructed in this paper to assist PE teaching. The whole system aims to make up for the defects of traditional PE teaching mode. On the one hand, it studies resource push technology, takes individual needs as the core and carries out learning resource allocation and individualized push for different students. On the other hand, it achieves interactive PE teaching system based on streaming media, supports the exchange and study between teachers and students, and breaks through the defect of time and place limits in traditional teaching. In this paper, the course of Skiing and Mountaineering Exercise was chosen as the test content to check the effect of this teaching system. The results show that interactive teaching based on video resource push technology can motivate students' learning initiative and interest and greatly improve the learning effect.
\end{abstract}

Keywords-Skiing and mountaineering, interactive, streaming media, Push technology, PE teaching

\section{Introduction}

Many defects exist in traditional education, which especially stands out in the education types stressing individuality cultivation and creativity such as PE and art. On the one hand, traditional education pays attention to "teaching". On the other hand, traditional education lays emphasis on unification rather than individuation and fails to really teach students in accordance with their aptitudes. Thirdly, traditional educa- 
tion form depends on existing inherent education resources. Due to single knowledge propagation mode and poor interactivity, it is very hard to motivate students' enthusiasm and creativity in the learning process, and "people-oriented" concept cannot be achieved. With the rapid development of information technology and network, multimedia technology is more and more widely applied. Multimedia resources contain rich resource types, including voice, image and video etc., and the manifestation patterns are more visual and abundant [1]. The inevitable development trend is to apply multimedia technology in education and achieve sharing of education resources. Many schools have started to try and explore relevant aspects. Interactive teaching refers to a teaching mode which develops on the basis of scaffolding instruction theory [2]. Interactive teaching is a kind of teaching method in which teachers and students focus on a problem or topic to exchange equally and interact independently under macroscopic teaching background and on the platform which can be entered freely from multiple points [3].

\section{Review of Research Status}

Nozari and Siamian explored whether the application of podcast multimedia training system influences motivation realization and students' study of the Arabic course in high school. The results show that the podcast multimedia system can significantly promote the study of Arabic course in high school [4]. Sayeski and Kennedy et al. tested the effect of multimedia modules on participants' $(\mathrm{N}=76)$ knowledge and skills about early reading instruction. The multimedia modules involved the basic literacy of phonology and phonics. The results indicate that the multimedia modules succeed in teaching the participants foundational literacy [5]. Austin put forward a multimedia teaching method - "ISSN Pending" and considered the Journal (ISSN Pending) aims to show extensive and multi-disciplinary positions on multimedia learning and the evaluation of presentation content so as to increase knowledge acquisition. The Journal is a peer-reviewed and cloud-based resource which is formatted in responsive web, and it may be evaluated by a $\mathrm{PC}$, laptop, tablet and smartphone simultaneously in 83 different languages. The results show that such new multimedia teaching method has a good teaching effect [6]. Tradition PE teaching mode is single. Teachers mostly teach students through explanation and demonstration. The exchanges between teachers and students are few, and students' learning enthusiasm cannot be well motivated [7-8]. Thus, the introduction of multimedia teaching system which integrates modern information in PE teaching field has become an inevitable trend for current teaching reform. Zhao peiyu and Ji Liewei et al proposed compute-supported exercise cognition learning strategy, designed and developed a sharing-based PE multimedia teaching system. The teaching resources in the system are partly applicable to online independent and collaborative learning, and partly applicable to synchronous assisted learning of gymnasiums. The system provides extensive teaching resources for independent and collaborative learning [9]. Armenteros and Liaw further understood different behavioral intentions of referees and assistant referees in diverse FIFA confederations to Multimedia Teaching Materials as the learning tools. 
They mainly considered Technology Acceptance Model, the Motivational Model and the Social Cognitive Theory. The results verify that multimedia teaching technology is accepted by the referees who consider such method is more beneficial to improve learning interest [10].

At present, most schools regard multimedia education resource construction as the key point of teaching investment, while multimedia video resource technology becomes the subject of teaching resource and network construction [11]. Currently, massive open online courses, micro-course, flipped classroom and other education video resources grow rapidly, provide rich learning resources for learners and also make them face the following problems. Firstly, the quality of education video resources is uneven, and high-quality resources are few. Secondly, education resource sharing platforms are mostly based on the objects, ignore the individuation feature of learners and cannot meet users' individualized learning needs fundamentally [12]. Finally, education resources are miscellaneous, and learners need to spend more time and energy in seeking useful resources, which greatly reduces learning efficiency [13].

The interactive teaching system based on education video resource push technology was constructed in this paper. The innovation of this system is that it introduces interactive teaching and resource push technology. (1) Interactive teaching adopts streaming media technology, and supports real-time video transmission. Under mobile $3 \mathrm{G}$ network and wifi environment, both parties can carry out video teaching through PC terminal or mobile devices such as smartphone and Pad without time and pace limits. Both parties can exchange and interact anytime. (2) The resource push technology based on feature extraction can choose the most suitable resource contents from massive resources according to the preset conditions, actively push and update at regular intervals. The individual difference label is identified as individual feature, and in-depth learning is adopted to extract the features of video resources and construct feature vector database of video resources. Then, feature matching algorithm is used to decide whether the video resource is pushed to learners.

\section{Model Analysis}

\subsection{Overall principle}

Any system can form a complete structure and give play to overall functions only through connecting internal and external environment. Only when courses, environment, teachers and students form a unified whole with mutual connection and interaction and promotion can the whole functions of teaching be shown. Meanwhile, the evaluation system of interactive teaching mode should focus on the whole, effect and process. None of them can be omitted. 


\subsection{Feedback principle}

The education system is too complex, and the set objective cannot be certainly reached. Before teaching, teachers need to set a teaching objective. Generally speaking, it is easy to confirm the knowledge objective. The ability aim and emotional attitude value cannot be confirmed easily. So, the final achievement of teaching objective is based on multiple feedbacks in the teaching process, including knowledge feedback, ability feedback and emotional attitude feedback. "One-way teaching" is completely eradicated in the teaching process. Feedback principle should be applied in the teaching process.

\subsection{Orderly principle}

Orderly principle gives a new enlightenment about how to carry out "exchangeinteraction" in the teaching process: the teaching system must be open; the teaching process should fluctuate and change; teaching activities should be organized through keeping away from the equilibrium state. Only new activities can form new forms, and then new cognition can be constructed. In this way, the teaching process becomes a "self-organization" process, rather than compulsive "other-organization" process.

The construction structure of interactive teaching theory in multimedia teaching is shown in Fig.1.

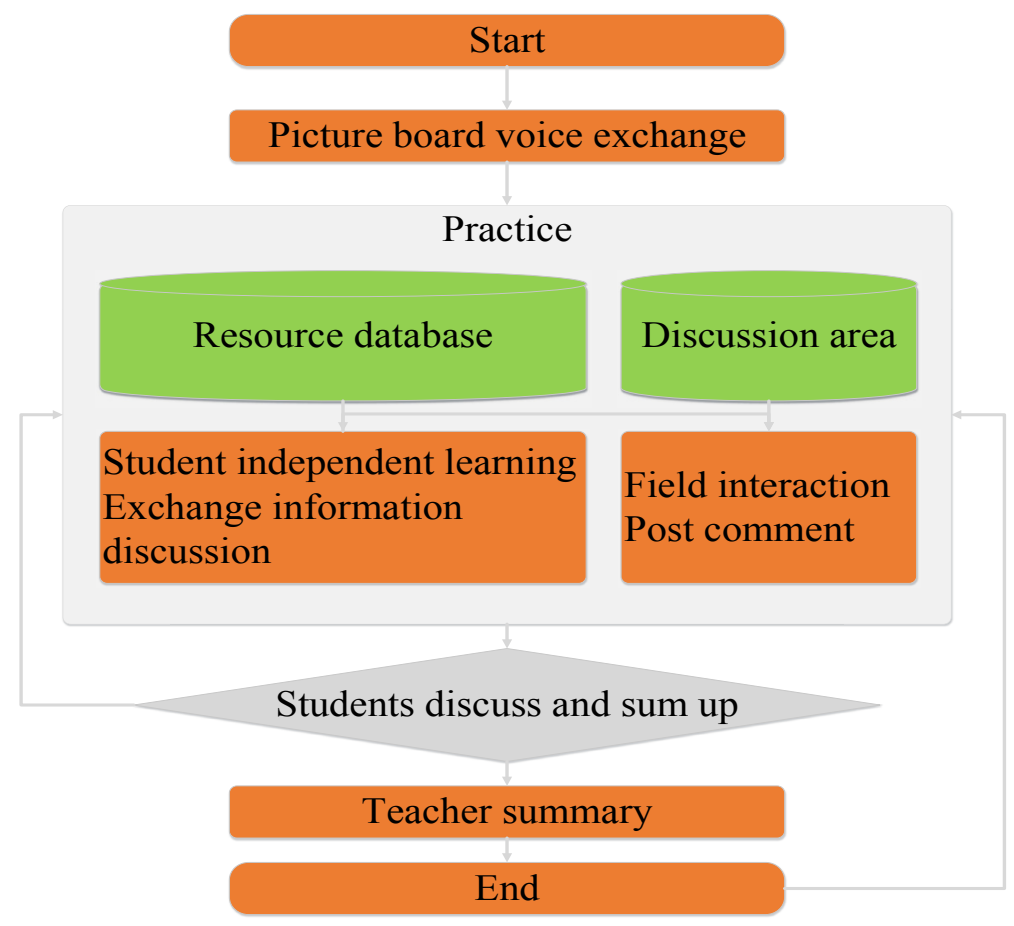

Fig. 1. Theory construction of interactive teaching 


\section{System Design}

This system mainly provides two types of services, as shown in Fig.2. Students may choose the service type according to their needs. The first service type is video recommendation. The recommendation function module actively pushes targeted video resources to users at a regular interval. The second service type is real-time teaching. It is supported by streaming media communication module. Both participants can exchange and interact in real time.

\subsection{Video recommendation module}

This system mainly includes the following parts: user resource modeling, learning video resource feature, and push by classification.

As shown in Fig.3, user resource modeling as the data foundation of the whole system aims to gather user information. The system guides users to input basic information through information interface as shown in Fig.4, including gender, age, height and weight etc. Meanwhile, users' hidden behavior data are mined, such as resource need description, click result, download times, collection records, resource evaluation and resource search records. The common data mining methods are diversified. For example, the Web log at the server will record students' learning behavior data. Cookie at the client will reserve information query records within certain time. When the data are more detailed, user resource will be described more accurately. Finally, the gathered data are integrated and analyzed to gain students' resource model. In this paper, the data gained by user information module include basic information (gender, age, height and age), interests and learning status, as shown in Fig.4.

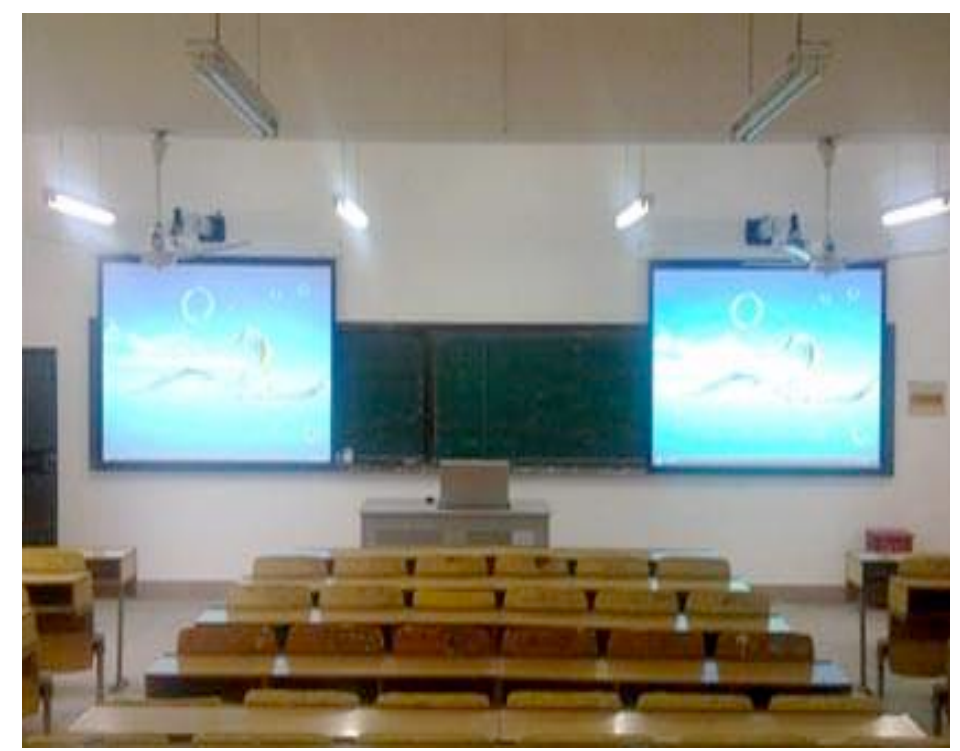

Fig. 2. Main interface of teaching type selection 


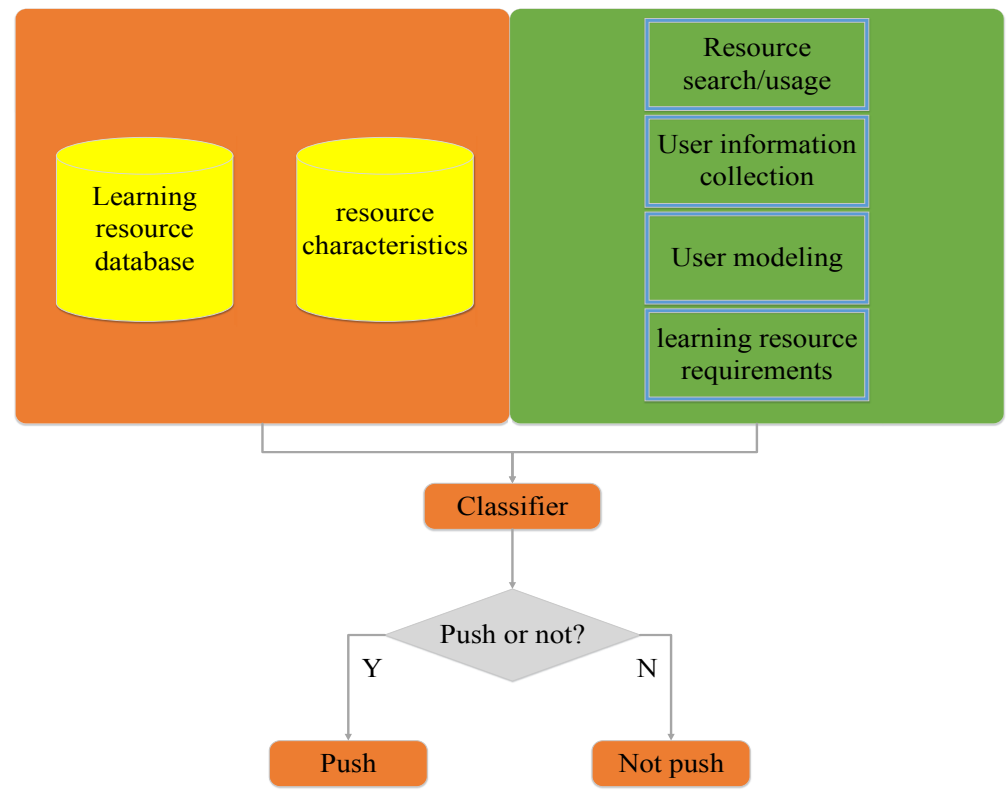

Fig. 3. Architecture of video recommendation module

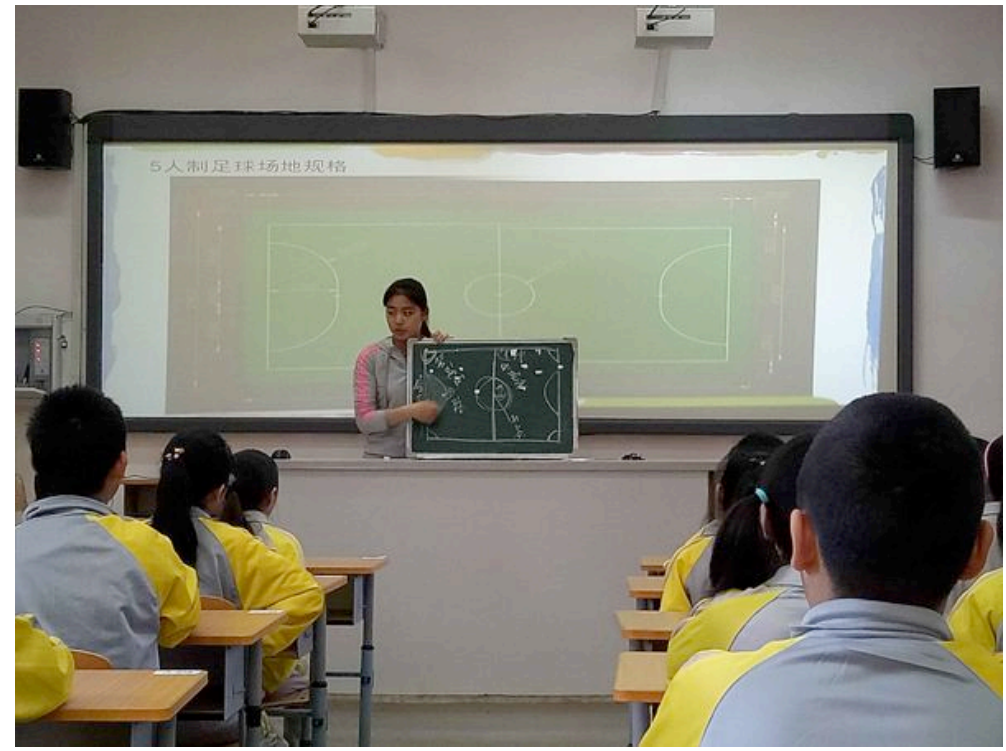

Fig. 4. Teaching demonstration of "sports training" based on video push technology

During extraction of video resource features, pre-training is required for relevant resource features. The new user behaviors may be continuously added in the training samples to enrich sample data and prepare conditions for establishing the relevance between user needs and resources. 
Pushing by classification requires pre-training of relevant resource features. Two different types of graphs represent two kinds of samples, i.e. choose to view and not to view the video in this paper. $\mathrm{H}$ is the classification line of two types. The goal of researching classification is to give resource matching recommendation according to users' need features, i.e. recommend suitable resources to students. Pushing by classification is divided into two stages: learn and actively push learning resources. It is necessary to train samples in the learning stage, and utilize the chosen learning resources and user need to generate feature vector. If the user clicks to choose the learning resource, it falls into $\mathrm{H} 2$, or else it falls into $\mathrm{H} 1$. For the feature vector generated by new user need, the position in the classifier is gained after analysis and processing. If it is close to $\mathrm{H} 2$, the resource is considered to be the resource which can be recommended. If it is close to $\mathrm{H} 1$, the resource is considered to be unsuitable for the user, and it will not be recommended.

\subsection{Video transmission module based on streaming media}

Streaming media transmission mode includes real-time stream transmission and progressive stream transmission. In the progressive stream transmission, the data can only be downloaded to PC terminal from the serve according to the order. Although it can make sure users view while downloading, since the order of video data arriving at the client is fixed, users cannot choose the playing position at will. Besides, it cannot support live broadcasting. The real-time stream transmission supports RTSP and other special protocols, allows real-time interaction and supports course recording, editing, classroom live broadcasting and live video etc. So, it is more suitable for the interactive teaching in this paper. Hence, real-time stream transmission mode is chosen to construct video transmission module.

As shown in Fig.5, the specific video player is installed in the system. The video request is sent to web server through web interface of the system. The web server transmits the request to the resource server after processing the request. The resource server and player establish mutual connection and transmit the required video data to the player for playing.

Architecture of interactive teaching module based on streaming media: As shown in Fig.6, interactive teaching module based on streaming media mainly includes three parts: student management, data interaction and streaming media teaching.

Student management part mainly manages students' basic data information, such as name, student number, account number and grade. It mainly completes information maintenance of new users and information management of existing users. Student login control is control access part and provides users with different resource use right according to users' identity and right. Since user database in the whole system is uniform, the functions of this part are shared with video push module.

Streaming media teaching includes real-time teaching interaction part and completes voice-based and video-based exchange. This part is the highlight of interactive teaching. Resource management manages teaching resource database and involves resource increase, editing and other operations. About resource recording and playing, 
the video and courseware may be made in advance for non-real-time video teaching. The recorded content will be added in the resource database as a new resource. Meanwhile, video-on-demand is supported for students to carry out preview and review.

Data interaction includes query system which checks students' learning effect. The feedback system handles users' resource description and service quality evaluation. It is used to assess the quality of video resources. The question answering system can provide question answering function in the form of text and video.

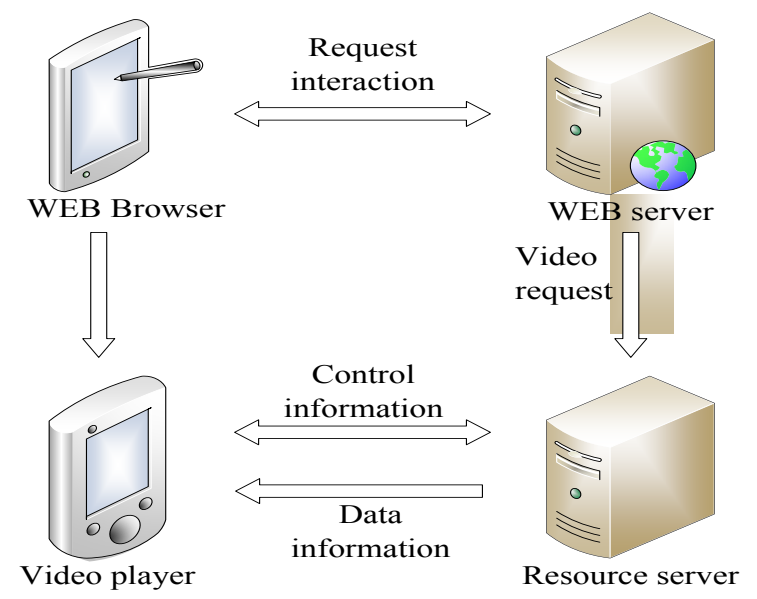

Fig. 5. Structure diagram of audio module

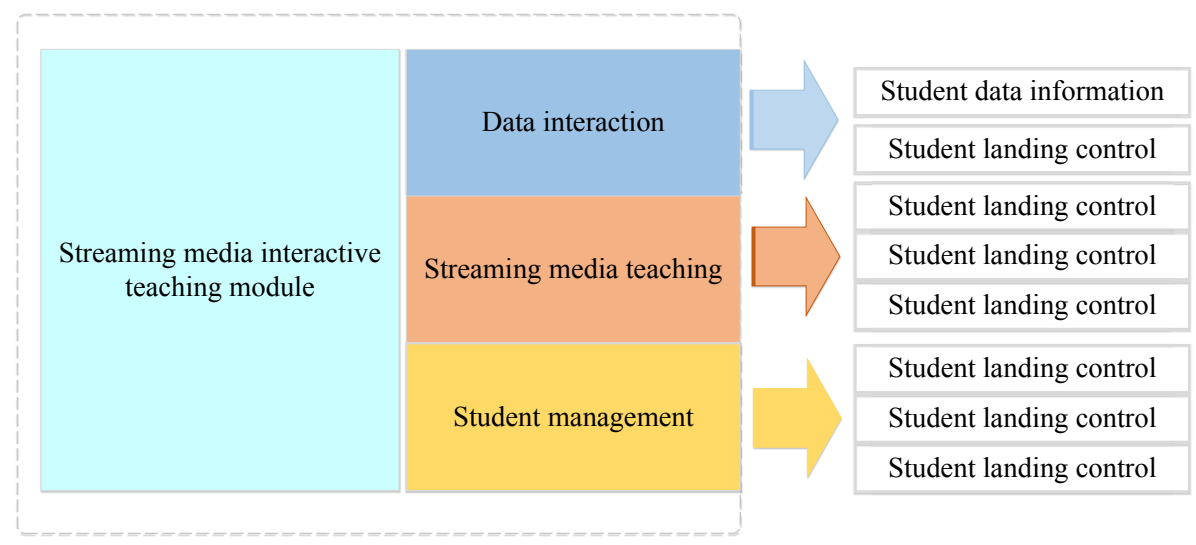

Fig. 6. System architecture of interactive teaching

Real-time video interaction: As shown in Fig.7, to complete real-time video interaction, both parties need to complete video/audio real-time connection, coding, decoding, storage and transmission process. The collection contents mainly contain video and audio. Video collection mainly depends on the camera and vidicon etc. Audio collection mainly depends on the microphone. 
Coding aims to process the collected data. Since the size of collected data is large and the direct transmission occupies too large storage space and network bandwidth, coding is carried out first to compress the data size. Before viewing the video, the receiver adopts the corresponding decoding method to decode the data and then view. The most common MPEG-4 coding method was applied in this paper.

Storage aims to finish data flow control. All the collected data are transmitted after the processing which may result in network transmission jam. Thus, storage control is adopted to balance transmission flow and ensure data transmission efficiency.

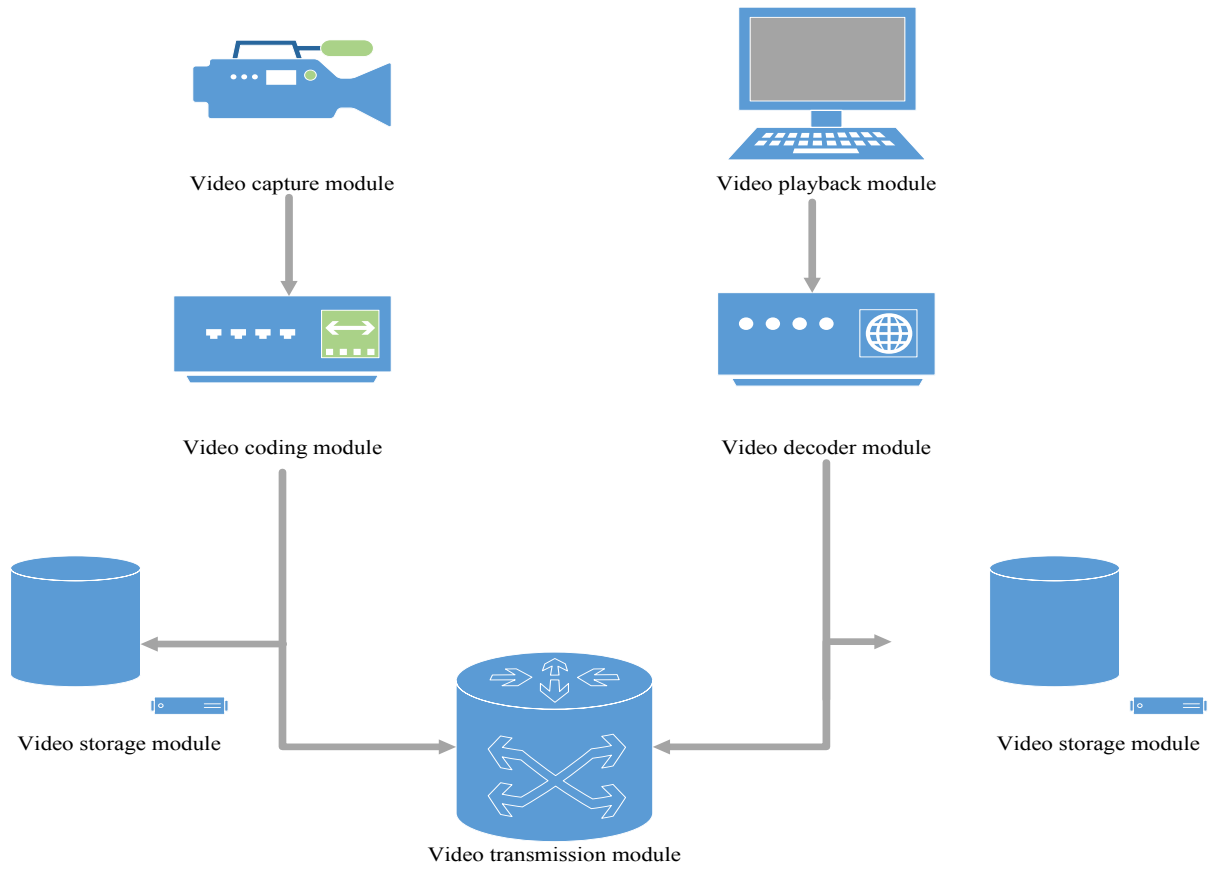

Fig. 7. Real-time data transmission flow

\subsection{Effect test}

To test the effect of this system on PE teaching, Skiing and Mountaineering Exercise of PE major in a school was chosen as the research course. Two classes were chosen from the freshmen in the senior high school as the objects of study. They were marked with Class A and Class B. The interactive teaching system was applied for Class A, while traditional teaching method was used for Class B. After 10-week study, 40 students were chosen at random respectively from Class A and Class B for the test. The questionnaire survey was adopted to investigate students' interest in the course. The course learning performance was scored by the teacher. The survey data results are as follows: 
Paper-Construction of Interactive Teaching System for Exercise Training Based on Education Video...

Table 1. Survey data table of students' interest in the course in the $5^{\text {th }}$ week

\begin{tabular}{|l|c|c|}
\hline \multicolumn{1}{|c|}{ Class } & No. & Number of students interested in the course \\
\hline Experimental class (Class A) & 40 & $23(57.5 \%)$ \\
\hline Control class (Class B) & 40 & $18(45 \%)$ \\
\hline
\end{tabular}

Table 2. Survey data table of students' interest in the course in the $10^{\text {th }}$ week

\begin{tabular}{|l|c|c|}
\hline \multicolumn{1}{|c|}{ Class } & No. & Number of students interested in the course \\
\hline Experimental class (Class A) & 40 & $29(72.5 \%)$ \\
\hline Control class (Class B) & 40 & $16(40 \%)$ \\
\hline
\end{tabular}

According to Tab.1 and Tab.2, under the same conditions, the number of students interested in the course in Class $\mathrm{A}$ and the ratio of students considering the course matches with their learning schedule in Class A are higher than those in Class B. In addition, the comparison of Tab. 1 and Tab. 2 shows that after a period, the number of students interested in the course and the number of students considering the course matches with their learning schedule in Class A rise by about 20\%. However, the changes for Class B are little and even the number drops slightly (the number of students interested in the course drops to $40 \%$ from $45 \%$ ). We can see from the above data that interactive teaching significantly improves students' interest and course pertinence so that students can learn more joyfully.

Table 3. Survey data table of students' course participation degree and learning effect

\begin{tabular}{|l|c|c|c|c|}
\hline \multirow{2}{*}{\multicolumn{1}{|c|}{ Class }} & \multirow{2}{*}{ No. } & \multicolumn{3}{c|}{ Learning effect } \\
\cline { 3 - 5 } & & Excellent & good & general \\
\hline Experimental class (Class A) & 40 & $40 \%$ & $35 \%$ & $25 \%$ \\
\hline Control class (Class B) & 40 & $10 \%$ & $55 \%$ & $35 \%$ \\
\hline
\end{tabular}

Statistical analysis of students' course participation degree and learning effect was conducted in the way of teacher's scoring. The data are shown in Tab.3. According to teacher's scoring, 60-70 means general; 70-85 means good; 85+ means excellent. The statistical result shows the ratio of excellence in the experimental class is much higher than that of control class, and the ratio of goodness and above is also higher than that of control class. This indicates this system enhances students' sense of course participation to certain degree and their learning effect also improves significantly.

\section{Conclusions}

The interactive teaching system based on education video resource push technology was constructed in this paper. Besides, the interactive teaching system was compared with traditional teaching mode. The results show students' course participation degree and interest improve after the introduction of interactive teaching. The push technology can filter education resources according to individual needs, solves the problem caused by information surplus and provides students with targeted and indi- 
vidualized teaching resource recommendation. The interactive teaching mode can make students think and explore actively. The whole teaching link is dominated by students, and led by the teacher. This really achieves exchange and interaction between teachers and students and among students. Such teaching and learning effect is obviously better than that of traditional teaching mode. Such teaching design has extensive market prospect and application potential, and provides reliable experience and reference for PE teaching or other multimedia teaching.

\section{Acknowledgment}

This work was supported in part by the 2017 annual social science projects of Beijing City education Department (SM201711417007).

\section{$7 \quad$ References}

[1] Granmo, M., Bengtsson, F. Teaching Anatomy in the Multimedia World-Using Digital Tools for Progressive Learning over Time, Creative Education, 2015, vol. 6(11), pp. 11931200. https://doi.org/10.4236/ce.2015.611117

[2] Zhou, H.Q. Theoretical research of scaffolding instruction, china education innovation herald, 2008, vol. 26(1), pp. 74-74.

[3] Lu, H.S. Interactive teaching model and its application in classroom teaching, China Adult Education, 2010, vol. 14(3), pp. 164-165.

[4] Nozari, A.Y., Siamian, H. The Effect of Applying Podcast Multimedia Teaching System on Motivational Achievement and Learning among the Boy Students, Acta Informatica Medica, 2015, vol. 23(1), pp. 29-32. https://doi.org/10.5455/aim.2015.23.29-32

[5] Sayeski, K.L., Kennedy, M.J., Irala, S.D., et al. The Efficacy of Multimedia Modules for Teaching Basic Literacy-Related Concepts, Exceptionality, 2015, vol. 23(4), pp. 237-257. https://doi.org/10.1080/09362835.2015.1064414

[6] Austin, R. Call for Papers International Journal of Multimedia Teaching and Content Assessment, Experiential, 2015, vol. 4(3), pp. 120-126.

[7] Li, Y.H. Multimedia teaching of Physical Education, China Information Technology Education, 2012, vol. 19(1), pp.103-104.

[8] Hernandez, P., Gonzalez, J.L. Application of Multimedia Technology to Study the Ordinal Competences of Children from 3 to 7 Years Old, International Journal for Technology in Mathematics Education, 2011, vol. 18(11), pp. 127-136.

[9] Zhao, P.Y., Ji, L.W., Li, S.B., et al. Practical research on shared Sports Multimedia Teaching System -- Research on computer supported Physical Education Collaborative Learning, Modern Educational Technology, 2010, vol. 20(2), pp. 146-149.

[10] Armenteros, M., Liaw, S.S., Sánchez-Franco, M.J., et al. Analysis of FIFA referees and assistant referees' motivational factors towards the Multimedia Teaching Materials, Education \& Information Technologies, 2015, pp. 1-32.

[11] Tiernan, P. An inquiry into the current and future uses of digital video in University teaching, Education and Information Technologies, 2015, vol. 20(1), pp. 75-90. https://doi.org/10.1007/s10639-013-9266-8

[12] Zhou, X., Sun, Y., Wei, L., et al. The research of "emotional assistant" in Modern Distance Education Video Teaching, e-Education Research, 2012, vol. 19(8), pp. 59-62. 
Paper-Construction of Interactive Teaching System for Exercise Training Based on Education Video...

[13] Wang, Z.Y. Application of streaming media technology in Distance Education Video Teaching, China education innovation herald, 2013, vol. 29(1), pp. 142-143.

\section{Authors}

Lizheng Zhang is a lecturer in the Beijing City University, Beijing 100083, China (zlzcsxy@sina.com).

Fatao Wang (corresponding author) is an associate professor in the College of Arts and Science, Beijing Union University, Beijing 100101, China (wftbld@sina.com).

Aili Qi is an associate professor in Information Engineering Department, Bijie 551700, China. (qiailili@yeah.net).

Article submitted 18 April 2017. Published as resubmitted by the authors 23 June 2017. 